\title{
TEACHING ANATOMY THROUGH VIRTUAL REALITY: A COMPARISON BETWEEN THE MAIN TOOLS
}

\author{
Mayara Sousa Stein, Maria Paula Corrêa Angeloni, Paula Casagrande Bristot \\ and Taliha Hoffmann Rahim \\ Universidade Federal de Santa Catarina \\ Araranguá, Brazil
}

\begin{abstract}
The evolution of technology has supported many areas like education, accountancy, health and other fields found on their intersections. It is also the case of applications for teaching human anatomy, where systems that use Virtual Reality are developed. With that in mind, this article has the intent to listen and compare the significant characteristics of the tools - such as platforms, frameworks, and engines - for creating Virtual Reality applications to teach anatomy and select the best of them through comparisons between their respective characteristics. For this purpose, an exploratory narrative review was carried out, resulting in the identification of the best tool to be used. The chosen tool, in turn, is entitled SOFA and presents ideal functionalities for this type of application due to the fact of having high-quality graphics, being open-source, amongst other essentials attributes necessary to reach the proposed goal.
\end{abstract}

\section{KEYWORDS}

Virtual Reality, Anatomy, Information and Communication Technologies

\section{INTRODUCTION}

According to Montero and Zanchet (2003), Virtual Reality (VR) has been benefiting medicine through many different applications developed to help teaching in the health field. These tools have been able to promote great assistance in education and reaching notable achievements like high-detailed exams, medical training, procedure simulation and anatomy teaching. They also present satisfactory results like cost-reduced procedures, the possibility of accessing detailed information, and allowing the same process to be carried out several times (Melo et al., 2007).

When developing medical applications using VR, one of the primary objectives of the developers is the modeling of three-dimensional objects, because there are significant difficulties in implementing a high degree of realism. Therefore, frameworks were developed to increase practicality and lower project-developing time, reusing available codes (Oliveira, 2007). Aiming to facilitate the development of applications, like games, the engines were created and offered an IDE (Integrated Development Environment) with a set of libraries and tools that made it easier to handle complex calculations (Dickson et al., 2017). Other than that, they provide support for virtual reality, sounds, artificial intelligence, file management, and programming.

Currently, there are some frameworks, platforms, and engines to VR applications, each one presenting its characteristics and advantages. That way, the research problem explored in this article is: which would be the best ones for the development of a virtual reality application to teach about the human anatomy? In the course of this article, some frameworks, platforms, and engines that support VR applications development will be presented, exposing their characteristics and utilization. The goal of this article is to compare tools specifications and present the fittest for the construction of this type of application. When analyzing different materials, the practicality of this technology in teaching is emphasized, considering that students can put into practice medical instructions. The present paper brings in its structure the introduction on the first chapter and the theoretical basis on the second. Then, the third chapter exposes the employed methodology, and the fourth and fifth present the achieved results and their conclusion, respectively. 


\section{TEACHING ANATOMY THROUGH VIRTUAL REALITY}

\subsection{Theoretical Foundation}

According to Turney (2007), the teaching and learning of anatomy are declining: the corpse using teaching modality deprives the student of obtaining a broader knowledge of the human anatomy. It can cause significant issues on the qualification of the professional, considering that archaic teaching requires reduction of class hours to teach anatomy in laboratories, due to the necessity of equipment availability and schedules to gain access to anatomy laboratories (Machado, 2011). Hence, different virtual reality applications are being developed to collaborate with teaching in the medical field. They offer interactivity and immersion in a virtual world that imitates elements from the real world using high resolution and refresh rate displays along with earpieces and motion sensors that allow reaching the user's senses entirely: sight, hearing and moving. Moro (2017) also emphasizes that three-dimensional virtual worlds are the ideal way to represent anatomical structures since the same ones in the real world are represented employing three-dimensional shapes. Using this technology, the student is able to study anywhere, not being tied to time restriction in laboratories, and still have a realistic experience. Tori (2009) has created a virtual atlas, to train medical students that can be accessed remotely from anywhere, using conventional computer equipment - even though the model only shows the virtual image projection, not allowing item manipulation on the scene. Izard, Méndez and Palomera (2017) present a 3D anatomy teaching tool that allows the users to interact with the environment, in ways that allow them to perform the assembly of a skull utilizing different bones through hand movements and commands.

To develop such applications, frameworks - considered "class libraries that support functionalities" and implement project standards - are usually employed (Machado, Morais and Nunes, 2009). According to Bastos, Raposo and Gattas (2005), the framework's importance is due to the fact that VR applications are of a high complexity and involve large development costs, so frameworks allow the developers to focus "only" on the development, not having to dedicate themselves to the management of the system. The frameworks can supply different resources like device and projection system abstraction, scene specialized graphs, heuristics of interaction with the virtual environment, support for distributed systems and distributed rendering (Bastos, Raposo and Gattas, 2005).

\subsection{Methodology}

In this chapter, it is reported how the research was performed, which methods were used to decide whether to include or exclude frameworks, platforms, and engines.

The narrative review in an exploratory way was utilized as a basis to carry out this work. According to Mesquita (2017), there is not a systematization to be followed: the selection of the documents is made arbitrarily. The researches to identify the tools were performed on Scopus, Scielo, Web of Science, IEEE, and Google Scholar databases. To reach the goal of this research - to compare the tools' specifications and present the most appropriate ones for the construction of an anatomy teaching application -, the theoretical basis was carried out to conceptualize and contextualize the subjects. Thereon, the selection of the tools that were going to be used for comparison was followed through. As for the research approach, it is classified as deductive and inductive.

\subsection{Evaluated Tools}

\subsubsection{Engines}

Among all the tools studied, an analysis of the characteristics that assist the development of a virtual reality application for teaching anatomy was performed. The engines found were Unreal Engine and Unity, which are used for game development and support virtual reality.

The engines are generally differentiated by scalability, portability, available features, graphics quality, costs and processing power (Macedo, Rodrigues and Serpa, 2015). Unity is suitable for developing games in either $2 \mathrm{D}$ or $3 \mathrm{D}$ and one of its robust features is the high-quality graphics for games but falls short when more realistic simulations are required. However, the modeling resources are presented intuitively and straightforwardly, making it possible to export projects to different platforms. 
Unreal Engine is also used to develop games, easy to be used and has an intuitive interface and modern state-of-the-art graphics. However, there is no support for modeling and requires a high-performance computer for developing applications (Paul, Goon and Bhattacharya, 2012).

\subsubsection{Frameworks}

The frameworks included in this work were selected because all of their applications are focused on the health area: Cybermed and CHAI3D.

Cybermed is an open source framework for medical applications developed by VirtWall platform. Its three-dimensional models allow the users to control and zoom for objects besides visualization in a monoscopic or stereoscopic way. The immersion can be done employing haptic interaction devices, which makes it more realistic thanks to the sensation of touching the object and the interactive deformation of the structures touched. The user can interact with the system through a mouse, keyboard or joystick.

CHAI3D was also developed for visualization and simulation of haptic interaction, having applications in games, teaching, and medical simulations. It was developed to be intuitive and easy to understand, offering a unique interface to design and easily implement advanced computer applications, as well as providing all the resources needed to develop static, dynamic and articulated bodies. Its graphical components are based on OpenGL and allow importing 3D models developed in applications such as Autodesk 3D Studio Max and Alias Wavefron (Pereira, 2010).

\subsubsection{Platforms}

The platforms found for VR applications applied in the health area were VR Juggler and SOFA. The first one provides an operating environment in which developers can test the available features of the application regardless of operating system and hardware configurations. The platform is open source and supports multiple graphical APIs. It was created with the intention of exploring advanced applications and the use of "immersive" systems that may not be as costly, bringing the cost-benefit advantage through an environment that provides developers with hardware configuration detail abstraction and other tools to provide bases for prototypes, development, testing, among other actions (Bierbaum, 2016).

SOFA, on the other hand, is a physics-based platform that aims to create real-time simulations, favoring the experience in the medical area (Bensoussan, Duriez and Grisoni, 2007). It is being used in applications such as electrophysiology and cardiac mechanics, use of catheters and needles, and deep brain stimulation. This is an open-source platform and its code is hosted on GitHub. The platform has over ten years of research, having several publications about its functionalities and many simulators based on it. Besides, it is based on a central API that offers features that can combine hundreds of components in a single simulation adapted to each application, causing the system to communicate transparently with others thus presenting the interoperability aspect (SOFA, 2018).

\subsection{Results and Discussions}

From the tools' main characteristics described, Table I was elaborated to compare the analyzed software. Based on the data listed, the engines, frameworks, and platforms used to develop Virtual Reality applications for the medical field will be analyzed. 
Table 1. Tools comparison

\begin{tabular}{|c|c|c|c|c|}
\hline Engine & Application & Advantages & Disadvantages & Functionalities \\
\hline Unreal Engine & $1-$ Games & $\begin{array}{l}1 \text { - Open source; } \\
2 \text { - Multiplatform }\end{array}$ & $\begin{array}{l}1 \text { - Modeling is not } \\
\text { supported; } \\
2 \text { - A state-of-the-art } \\
\text { computer is required } \\
\text { for development }\end{array}$ & $\begin{array}{l}1 \text { - Particle effects, } \\
\text { including volume and } \\
\text { shade; } \\
2 \text { - Production of } \\
\text { cutscenes or films; } \\
3 \text { - Visual debugging } \\
\text { at runtime }\end{array}$ \\
\hline Unity & 1 - Games & $\begin{array}{l}1 \text { - Pre-made models; } \\
2 \text { - Free version } \\
\text { available; } \\
3 \text { - Multiplatform }\end{array}$ & $\begin{array}{l}1 \text { - Modeling is not } \\
\text { supported; } \\
2 \text { - A payment is } \\
\text { required to be able to } \\
\text { sell a game }\end{array}$ & $\begin{array}{l}1 \text { - Libraries to create } \\
\text { the entire game; } \\
2 \text { - Support for } \\
\text { sounds, artificial } \\
\text { intelligence, etc }\end{array}$ \\
\hline \multicolumn{5}{|l|}{ Framework } \\
\hline Cybermed & $\begin{array}{l}\text { 1-Simulator for training; } \\
2 \text { - Stereo multilayer view; } \\
3 \text { - Haptic Properties Calibrator }\end{array}$ & $\begin{array}{l}1-\text { Open source; } \\
2-\text { Tests and } \\
\text { evaluation are carried } \\
\text { out constantly }\end{array}$ & $\begin{array}{l}1 \text { - High cost; } \\
2 \text { - Previous } \\
\text { knowledge in } \\
\text { programming }\end{array}$ & $\begin{array}{l}1-\text { Monoscopic or } \\
\text { stereoscopic view; } \\
2-\text { Virtual objects, } \\
\text { such as tomography, } \\
\text { resonance magnetic, } \\
\text { medical examination }\end{array}$ \\
\hline CHAI3D & $\begin{array}{l}1 \text { - Planning, training, robotics, } \\
\text { neurosurgery and aerospace; } \\
2-\text { Surgical simulation }\end{array}$ & $\begin{array}{l}1 \text { - Open source; } \\
2 \text { - Creation of high- } \\
\text { performance haptic } \\
\text { applications }\end{array}$ & $\begin{array}{l}1 \text { - Only for } \\
\text { developers }\end{array}$ & $\begin{array}{l}1-\text { Extension } \\
\text { modules; } \\
2-\text { Support for ODE } \\
\text { and GEL to simulate } \\
\text { rigid and deformable } \\
\text { bodies in real time }\end{array}$ \\
\hline \multicolumn{5}{|l|}{ Platform } \\
\hline VR Juggler & 1 - VR app development & $\begin{array}{l}1 \text { - Open source; } \\
2 \text { - Support for } \\
\text { graphic APISs }\end{array}$ & None & $\begin{array}{l}1 \text { - Provides an } \\
\text { object-oriented } \\
\text { development } \\
\text { environment }\end{array}$ \\
\hline SOFA & $\begin{array}{l}\text { 1-Advanced Heat Transfer; } \\
\text { 2-Cardiac Electrophysiology; } \\
\text { 3-Cardiac Mechanics; } \\
\text { 4-Catheters and Needles; } \\
\text { 5 - Deep Brain Stimulation; } \\
\text { 6- Medical simulation }\end{array}$ & $\begin{array}{l}1 \text { - Open and hosted } \\
\text { code in GitHub; } \\
2 \text { - Main medical } \\
\text { simulation software }\end{array}$ & None & $\begin{array}{l}1 \text { - Uses new } \\
\text { generations of GPUs; } \\
2 \text { - Visualization and } \\
\text { simulation of medical } \\
\text { images }\end{array}$ \\
\hline
\end{tabular}

All the analyzed tools presented essential aspects: Unreal Engine allows developing the entire application at no cost; however, it is necessary paying to launch the application (Pachoulakis and Pontikakis, 2015). Unity Engine, by contrast, has free versions that differ from the paid one for having fewer available resources (Macedo, Rodrigues and Serpa, 2015). The Unity Engine has low scalability, does not support realistic simulations and does not present interactivity between machine and user, and for that reason, it is not advisable to be used in the medical area (Macedo, Rodrigues and Serpa, 2015). SOFA and Cybermed have specific functionalities for the development of medical applications (Sales, 2010).

The studied tools have different functionalities, but the SOFA platform seemed to be the most complete tool among all the analyzed ones, as it supports developers, allows the users to model and interact with objects, create complex simulations combined with existing algorithms and use drivers for VR devices, haptics, and simulation.

\section{CONCLUSION}

Based on the frameworks, engines, and platforms evaluated, it is possible to answer the research question that seeks to identify the best tools for the development of a Virtual Reality human anatomy teaching application. Taking into account cost, performance, evolution, functionality, compatibility, and applications in the medical 
field, the SOFA platform stands out as the most appropriate to achieve this objective. It stands out for presenting the main functionalities for developing applications for virtual reality, especially medical applications, and for being open-source.

The comparison of the main researched tools for the development of a VR application that seeks to teach human anatomy, through the analysis of frameworks, engines, and platforms, is necessary to contribute to the development of a new software that aims to aid the teaching of anatomy. It is expected that future work will understand the comparisons and specifications of the tools described, facilitating the selection of suitable tools for this type of application.

\section{REFERENCES}

Bastos, T. A., Raposo, A. B. and Gattas, M., 2005. Um Framework para o Desenvolvimento de Aplicações de Realidade Virtual Baseados em Componentes Gráficos. XXV Congresso Da Sociedade Brasileira De Computação, pages 213-223.

Bensoussan, P, Duriez, C and Grisoni, L., 2007. SOFA - an Open Source Framework for Medical Simulation SOFA - an Open Source Framework for Medical Simulation. Medicine Meets Virtual Reality, pages 13-18.

Bierbaum, A. et al, 2016. VR Juggler: A Virtual Platform for Virtual Reality Application Development. Virtual Reality, 2001. Proceedings. IEEE, pages 89-96.

Dickson, P. E. et al, 2017. An Experience-based Comparison of Unity and Unreal for a Stand-alone 3D Game Development Course. ACM Conference on Innovation and Technology in Computer Science Education - ITiCSE '17, pages 70-75.

Izard, S. G., Méndez, J. A. J. and Palomera, P. R., 2017. Virtual Reality Educational Tool for Human Anatomy. Journal of Medical Systems, pages 2-7.

Macedo, D. V., Rodrigues, M. A. F. and Serpa, Y. R., 2015. Desenvolvimento de Aplicações Gráficas Interativas com a Unreal Engine 4. Revista de Informática Teórica e Aplicada, pages 181-202.

Machado, L. S., Moraes, R. M. and Nunes, F. L. S., 2009. Serious Games para Saúde e Treinamento Imersivo. Sociedade Brasileira de Computação, pages 31-60.

Machado, L. S. et al, 2011. Serious games baseados em realidade virtual para educação médica. Revista Brasileira de Educação Médica, pages 254-262.

Melo, J. S. S. et al, 2007. Uso da Realidade Virtual em Sistemas Tutores Inteligentes Destinados ao Ensino de Anatomia Humana. Simpósio Brasileiro de Informática na Educação - SBIE, pages 51-54.

Mesquita, G. B., 2017. O que fazem o community manager e o editor de mídias sociais em dois veículos de referência: ciberjornalismo ou marketing? Revista Observatório.

Montero, E. F. S. and Zanchet, D. J., 2003. Realidade virtual e a medicina. Acta Cirúrgica Brasileira.

Moro, C. et al, 2017. The effectiveness of virtual and augmented reality in health sciences and medical anatomy. Anatomical Sciences Education, pages 549-559.

Oliveira, A. M. T. G., 2007. ViMeT - Projeto e Implementação de um framework para aplicações de treinamento médico usando realidade ViMeT. Centro Universitário Eurípides de Marília, Fundação de Ensino Eurípides Soares da Rocha.

Pachoulakis, I. and Pontikakis, G., 2015. Combining features of the Unreal and Unity Game Engines to hone development skills. arXiv, pages: $1-5$.

Paul, P. S., Goon, S. and Bhattacharya, A., 2012. History and comparative study of modern game engines. International Journal of Advanced Computed and Mathematical Sciences, pages 245-249.

Pereira, R., 2010. Framework para o Desenvolvimento de Experiências Virtuais com Interação Háptica. Faculdade de Engenharia da Universidade do Porto.

Sales, B. R., 2010. Colaboração em Sistemas de Realidade Virtual voltados ao Treinamento Médico: um Módulo para o Framework CyberMed. Universidade Federal da Paraíba, Departamento De Pós-Graduação de Informática (PPGI) - UFPB.

SOFA, 2018. Framework SOFA. IEEE Robotics and Automation Letters, pages 2160-2165.

Tori, R. et al, 2009. VIDA: Atlas Anatômico 3D Interativo para Treinamento a Distância. Society, pages 1801-1810.

Turney, B., 2007. Anatomy in a Modern Medical Curriculum. The Annals of The Royal College of Surgeons of England, pages 104-107. 